\title{
Disclosure of HIV Positive Status: A Challenge Facing HIV Control, Alexandria, Egypt
}

\section{${ }^{1}$ Mona Hamdy Ashry, ${ }^{2}$ Maha Abdel Hameed and ${ }^{3}$ Fatma Tharwat Mohammed}

${ }^{1}$ Public Health \& Community Medicine Faculty of Medicine, Alexandria University, Egypt

${ }^{2}$ Alexandria Hepatology, Gastroentrology and Infectious diseases hospital, El Hadara, Alexandria, Egypt ${ }^{3}$ Pharmacist - Alexandria Hepatology , Gastroentrology and Infectious diseases hospital, El Hadara, Alexandria

Received: July, 2018 Accepted: October, 2018

\begin{abstract}
Background: Egypt is reported to have a growing HIV epidemic especially among injecting drug users and men who have sex with men. There is no published research studying disclosure among those living with HIV in Egypt. The study aimed to estimate disclosure rate, motives, barriers, consequences, and association with sexual behavior. Methods: Eighty (80) people living with HIV -16 years old and above- were selected using a systematic random technique from those regularly attending Alexandria National AIDS program center for treatment supply. A designed semi-structured interview questionnaire was used to collect data. Results: Self disclosure rate was $\mathbf{7 8 . 8 \%}$. Socially unaccepted behaviors associated with HIV transmission are significantly associated with non disclosure. Seeking support was the main motive. Sister and mother were first to disclose to $(79.3 \%)$. Anger and rejection was significantly associated with disclosure of HIV transmission through socially unaccepted behaviors. Denial of disease was the parents' reaction in $4.8 \%$. Female sex workers and men having sex with men were regretting disclosure to their sexual partners in most occasions and usually have unprotected sex. Conclusion: Culture, traditions, and religious beliefs play an important role in disclosure motives and consequences in Egypt. Public awareness regarding disease nature and high risk behaviors, and encouraging screening among high risk behavior groups should be integrated in the control program. Disclosure of HIV status and having protected sex should be discussed with all HIV diagnosed cases irrespective of their marital status.
\end{abstract}

Key words: HIV; AIDS; Disclosure; Unprotected sex; Egypt

Corresponding Author :Mona Hamdy Ashry drmonahamdy@gmail.com

\section{Introduction}

As the whole world is facing a Human Immunodeficiency Virus (HIV) pandemic, The Eastern Mediterranean Region (EMR) is ranked the first World Health Organization (WHO) region with an expanding epidemic. There is growing number of cases diagnosed with HIV all over the region. ${ }^{1}$ Egypt is reported to have a growing epidemic especially among injecting drug users and men who have sex with men in spite of the Egyptian National AIDS program efforts. ${ }^{2,3}$

Disclosure of HIV sero-positive status is a difficult and stressful matter. The association of HIV infection with drug use and sexual behavior often makes HIV +ve 
persons not accepted in the society., 4 Egypt is an Arabic and Islamic country where drug use, extramarital sexual relations and homosexuality are criminalized. Those involved in these acts are usually rejected by the society and accused of guilt and shame. ${ }^{3,6}$ Interruption of social relationships with family and friends, stigma, discrimination, and violence are common risks associated with disclosure of one's HIV positive status. ${ }^{4,5,7}$ On the other hand, disclosure of HIV +ve status was proved to have a good impact on individual's health. It prevents social isolation, improves self esteem with subsequent compliance with treatment and improvement of physical health. It also has a marked impact on preventing transmission of infection by decreasing probabilities of unprotected sex as well as other risky behaviors. 8,9

The Egyptian National AIDS program is focusing mainly on providing HIV testing, counseling, and Antiretroviral therapy. The last published report from the program stated that several studies were conducted to estimate population and gender affected, and to assess preventive measures, cost benefit analysis of prevention, stigma, and test-treat-retain care cascade. On the other hand, there is no published research studying disclosure of HIV status among those living with HIV in Egypt. ${ }^{3,10,11,12}$

The present study aimed to estimate self disclosure rate among those living with HIV in Alexandria, Egypt; and to identify disclosure motives, barriers, consequences, and association with sexual behavior.

\section{Methods}

A cross sectional survey was conducted among people living with HIV in Alexandria, Egypt. The study was carried out in Alexandria Hepatology; Gastroenterology; and Infectious diseases hospital (formerly Alexandria Fever
Hospital). It is a specialized governmental hospital providing health services to HIV/AIDS patients as one of the national AIDS program centers. It serves four Egyptian governorates.

Target population and sampling: There were 813 HIV positive registered cases in the study center during the year 2016. Only 450 cases were regularly attending the center for their monthly supply of antiretroviral treatment. The target population included all HIV positive cases who are regularly attending the center. Those below 16 years of age were excluded as they don't have ID card to receive the treatment supply by themselves.

For calculation of minimum sample size required, Epi Info ${ }^{\mathrm{TM}} 7$ software (CDC, Atlanta) was used. Based on 450 cases as target population, $90 \%$ reported disclosure rate $^{4}$ and $95 \%$ confidence level; the minimum sample size required is 80 cases. Eighty HIV +ve cases aged 16 years and above were selected using a systematic random sampling technique.

Data collection: Data was collected using a designed semi-structured interview questionnaire format. The questionnaire was designed to collect data regarding cases' socio-demographic characteristics, high risk behavior associated with catching infection, duration since diagnosis, HIV serostatus of husband/wife, self-disclosure, disclosure motives and barriers, relation to persons who disclosed to, immediate and late consequences of disclosure, and cases disclosure behavior with their sexual partners.

\section{Ethical considerations}

An ethical approval from Alexandria Faculty of Medicine Ethics Committee and Egyptian Ministry of Health were obtained. The aim of the study was clarified to each participant before enrolment. Privacy and confidentiality 
were ensured all through the research work conduction.

Data analysis: Data were analyzed using The Statistical Package for Social Sciences SPSS, version 18 (SPSS Inc, Chicago). Participants' responses in the semistructured interview questionnaire were organized and coded before data entry. Quantitative variables were presented as range, mean and standard deviation. For qualitative variables, frequency and percentage from total were used. ChiSquare test of significance was used to assess the association between disclosure behavior and the risk behavior associated with catching the infection. 5\% level of significance was used to interpret the result.

\section{Results}

The age of the studied cases ranged from 19 to 65 years with a mean age of $36.13 \pm 12.3$ years. Males constituted $51.3 \%$ $(n=41)$ of the total sample. As regard their marital status, slightly more than one third (36.3\%, $\mathrm{n}=29)$ were single. Married, widow and divorced represented $(27.5 \%$, $19 \%$, and $10 \%$ ) respectively. Table one shows the educational and occupational status of studied cases.

As regard the high risk behavior associated with HIV transmission, half of the studied cases $(50 \%, \mathrm{n}=40)$ had either drug addict HIV +ve husband $(n=37)$ or HIV +ve wife $(n=3)$. The remaining cases were either men who have sex with men $(40 \%, \mathrm{n}=32)$, injecting drug addicts $(7.5 \%, \mathrm{n}=6)$, or female sex workers $(2.5 \%, \mathrm{n}=2)$. The duration since diagnosis with HIV infection ranged from 1 to 22 years (3.98 \pm 4.1 years). The majority of studied cases $(78.8 \%, \mathrm{n}=63)$ disclosed their HIV +ve status to others. The high risk behavior associated with HIV transmission is significantly associated with disclosure of HIV +ve status $\left(X^{2}=6.05, P=0.014\right)$. The majority $(90 \%, \mathrm{n}=36)$ of those who caught the infection through sexual relations with Table (1) Distribution of studied people living with HIV according to their education and occupation

\begin{tabular}{|c|c|c|}
\hline Social characteristics & $\begin{array}{l}\text { Frequency } \\
(n=80)\end{array}$ & $\%$ \\
\hline \multicolumn{3}{|l|}{ Education } \\
\hline - Illiterate & 22 & 27.5 \\
\hline $\begin{array}{l}\text { - Read \& write / Basic } \\
\text { education }\end{array}$ & 17 & 21.2 \\
\hline - Secondary & 23 & 28.8 \\
\hline - University \& higher & 18 & 22.5 \\
\hline \multicolumn{3}{|l|}{ Working status } \\
\hline No & 44 & 55 \\
\hline Yes & 36 & 45 \\
\hline $\begin{array}{l}\text { Professional } \\
\text { semiprofessional }\end{array}$ & 14 & 38.9 \\
\hline - Skilled / semiskilled & 19 & 52.8 \\
\hline - manual & 3 & 8.3 \\
\hline
\end{tabular}

their husband/wife disclosed their serostatus compared to $(67.5 \%, \mathrm{n}=27)$ of those who caught the infection through socially unaccepted risky behaviors (Table 2).

Table (2) Distribution of studied people living with HIV according to the risk factor associated with infection and self Disclosure of their serostatus

\begin{tabular}{|c|c|c|c|}
\hline \multirow{2}{*}{$\begin{array}{c}\text { Risk factor } \\
\text { associated } \\
\text { with HIV } \\
\text { infection }\end{array}$} & \multicolumn{2}{|c|}{ Self Disclosure $(n=80)$} & $X^{2}$ test \\
\hline & Yes & No & \multirow{5}{*}{$\begin{array}{c}X^{2}=6.05 \\
P=0.014^{*}\end{array}$} \\
\hline $\begin{array}{l}\text { Transmission } \\
\text { from infected } \\
\text { husband/wife }\end{array}$ & $36(90 \%)$ & $4(10 \%)$ & \\
\hline $\begin{array}{l}\text { Risky } \\
\text { behavior }\end{array}$ & $27(67.5 \%)$ & $13(32.5 \%$ & \\
\hline $\begin{array}{l}\text { - Men have } \\
\text { sex with men } \\
\text { - Injecting } \\
\text { drug addicts } \\
\text { - Female sex } \\
\text { workers }\end{array}$ & \multicolumn{2}{|l|}{$2(2.5 \%)$} & \\
\hline Total & $63(78.8 \%)$ & $17(21.2 \%)$ & \\
\hline
\end{tabular}

Barriers to disclosure as stated by those who kept their HIV status secret $(n=17$, $21.2 \%$ ) are revealed in table (3).

Among those who disclosed their HIV +ve status $(n=63), \quad(71.4 \%, n=45)$ disclosed their sero-status immediately after diagnosis. Sister and mother were the first choice for disclosure $(79.3 \%)$. With time 
pass after diagnosis, all of them $(n=63)$ disclosed to one or more of their first

Table (3) Distribution of disclosure barriers among studied people living with HIV who didn't disclose their sero-status

\begin{tabular}{|c|c|c|}
\hline Disclosure barriers* & Frequency & $\%$ \\
\hline $\begin{array}{l}\text { Fear of rejection by family } \\
\text { and friends }\end{array}$ & 14 & 43.8 \\
\hline Fear of Stigma & 13 & 40.6 \\
\hline $\begin{array}{l}\text { Fear of secondary } \\
\text { disclosure to others }\end{array}$ & 3 & 9.3 \\
\hline $\begin{array}{l}\text { Fear of family } \\
\text { stigmatization by others }\end{array}$ & 2 & 6.3 \\
\hline Total responses & 32 & 100 \\
\hline
\end{tabular}

Table (4) Distribution of studied people iving with HIV who disclosed their serostatus according to time of disclosure and persons who disclosed to

\begin{tabular}{|l|r|r|}
\hline Disclosure time \& persons & $\begin{array}{c}\text { Frequency } \\
\mathbf{n = 6 3}\end{array}$ & $\%$ \\
\hline Time of first disclosure & 45 & 71.4 \\
\hline Immediately after diagnosis & 9 & 14.3 \\
\hline $\begin{array}{l}\text { Less than one year after } \\
\text { diagnosis }\end{array}$ & 9 & 14.3 \\
\hline $\begin{array}{l}\text { More than one year after } \\
\text { diagnosis }\end{array}$ & & \\
\hline First one to disclose to & 30 & 47.6 \\
\hline Sister & 20 & 31.7 \\
\hline Mother & 7 & 11.1 \\
\hline Father & 3 & 4.8 \\
\hline Daughter/son & 3 & 4.8 \\
\hline Friends
\end{tabular}

Persons who disclosed to other than the sexual partner*

\begin{tabular}{|l|r|r} 
Close friends & 13 & 20.6 \\
\hline
\end{tabular}

Work owners

*cases were asked to report all who disclosed to i.e. categories are not mutually exclusive

degree family members (i.e mother, father, sister, brother, old children). (Table 4)

The main motive for disclosure was the need for psychological, social, and financial support $(77.8 \%, \mathrm{n}=49)$. Among ten cases $(15.9 \%)$, HIV status was accidentally disclosed at the time of first hospitalization or on receiving laboratory investigation results. Two widow female cases $(3.2 \%)$ from rural areas had to disclose to their old children to get an excuse for travelling to Alexandria city monthly for receiving her antiretroviral treatment supply. Only one female case (1.6\%) disclosed to her work owner to set an excuse for absenteeism in case of illness and for going to receive her monthly antiretroviral treatment supply.

Immediate reaction for disclosure varied from sympathy $(75.1 \%, \mathrm{n}=36)$ to anger and rejection $(38.1 \%, \mathrm{n}=24)$. Three cases $(4.8 \%)$ stated that their parents completely deny their illness when they disclosed to them. Those cases explained their parents' reaction by those illiterate parents didn't know the nature of that disease and the cases are totally asymptomatic. There is a significant association between the immediate reaction and the high risk behavior associated with HIV transmission. Sympathy was felt by all disclosed cases who caught the infection through sexual relations with their spouses $(n=36)$. On the other hand, after exclusion of the three cases that parents deny their illness, all disclosed cases that caught the infection through other routes $(n=24)$ were faced by immediate anger and rejection (Table 5). The late reactions following disclosure are shown in table (6). Those cases who received the needed psychological support and social support following disclosure stated that this lead to improvement in their physical and mental health and compliance with treatment.

As regard the disclosure behavior of studied cases with their sexual partners, all studied females $(n=37)$ and males $(n=3)$ that caught the infection through sexual relations with their husband/wife were diagnosed at the same time with their spouses. Three studied drug addicts (50\%) were married and their wives were diagnosed at the same time while the other three drug addicts $(50 \%)$ were divorced long time before diagnosis. On the other hand, the studied female sex workers and 
men who have sex with men stated that

they were regretting disclosure of their Table (5) Distribution of studied people living with HIV who disclosed their sero-status according to the risk factors associated with infection and immediate reactions following disclosure

\begin{tabular}{|c|c|c|c|c|}
\hline \multirow{2}{*}{$\begin{array}{l}\text { Risk factors associated } \\
\text { with HIV infection }\end{array}$} & \multicolumn{3}{|c|}{$\begin{array}{l}\text { Immediate reaction following Disclosure } \\
\qquad(\mathrm{n}=63)\end{array}$} & \multirow{2}{*}{$\begin{array}{l}\text { Monte } \\
\text { Carlo test }\end{array}$} \\
\hline & Sympathy & Anger/ rejection & Denial & \\
\hline Infected husband/wife & $36(100 \%)$ & 0 & 0 & \multirow{3}{*}{$\mathrm{P}<0.001^{*}$} \\
\hline Risky behavior & 0 & $24(88.9 \%)$ & $3(11.1 \%)$ & \\
\hline Total & $36(57.1 \%)$ & $24(38.1 \%)$ & $3(4.8 \%)$ & \\
\hline
\end{tabular}

HIV serostatus to their sexual partners in most occasions and they usually have unprotected sex.

\section{Discussion}

Disclosure of HIV positive status is inversely related to the degree of stigma posed by the society. Stigma associated with high risk behaviors attributed to HIV transmission usually acts as a barrier against disclosure. ${ }^{13,14}$ This can explain the significant association found between socially unaccepted risky behaviors and non disclosure in the studied sample. It also explains the disclosure barriers stated by those who didn't disclose their HIV status. However, only $1.6 \%$ of those who actually disclosed their positive HIV status felt stigma following disclosure and this may be attributed to selective disclosure strategy adopted by them as most of them disclose to their mother and sister. Although the National AIDS program efforts succeeded in lowering stigma in health care settings affiliated to the program $^{3}$ but at the community level, negative attitudes and stigma is almost universally associated with HIV/AIDS. ${ }^{6}$

The need for psychological and social support was the main motive behind disclosure of HIV status. This is similar to what was reported by several studies conducted in different countries with different cultures and reflecting the life long, stigmatizing, infectious nature of that disease. ${ }^{7-9,13,14}$ Two of the studied widowed females had to disclose their HIV status to their old children to take an excuse for travel to Alexandria city for receiving the monthly treatment supply. This raised a new motive for disclosure not previously reported in reviewed literature and attributed to the Egyptian traditions especially in rural areas which give men the right to control over women's movement.

As a reflection to the revealed main motive behind disclosure, sister and mother were the first one to disclose to by the majority of cases. They represent the trusted family members who usually expected to give the needed support. ${ }^{15,16}$

Studied cases that caught the infection through sexual relations with their spouses were considered victims by their family members as revealed by the immediate reaction followed disclosure. On the other hand, those who caught the infection by socially unaccepted risky behaviors were faced by negative reactions. So; stigma, discrimination, and rejection associated with HIV are not a matter of disease infectivity but it is a matter of association with unaccepted risky behavior by the Egyptian community. The complete denial of the possibility of having HIV as a response to disclosure that reported by three cases may be attributed to the low level of HIV/AIDS knowledge reported in Egypt health issues survey where only $70.5 \%$ of studied men and women have heard about HIV/AIDS.6

Disclosure of HIV positive status to sexual partners is considered a corner stone in 
disease control. With the increasing numbers of newly diagnosed HIV cases, Table (6) Distribution of studied people living with HIV who disclosed their serostatus according to late reactions following disclosure

\begin{tabular}{|l|r|r|}
\hline \multicolumn{1}{|c|}{$\begin{array}{c}\text { Late reactions following } \\
\text { disclosure* }\end{array}$} & $\begin{array}{c}\text { Frequency } \\
\mathbf{n = 6 3}\end{array}$ & \% \\
\hline $\begin{array}{l}\text { Receiving support from } \\
\text { some family members \& } \\
\text { friends }\end{array}$ & 44 & 69.8 \\
\hline $\begin{array}{l}\text { Avoidance by some family } \\
\text { members }\end{array}$ & 23 & 36.5 \\
\hline Avoidance by friends & 8 & 12.7 \\
\hline $\begin{array}{l}\text { Feel of stigma by family } \\
\text { and friends }\end{array}$ & 5 & 7.9 \\
\hline Complete denial of disease & 3 & 4.7 \\
\hline $\begin{array}{l}\text { Family harming and } \\
\text { stigmatization by others }\end{array}$ & 1 & 1.6 \\
\hline Divorce & 7 & 14.6 \\
\hline
\end{tabular}

*Categories are not mutually exclusive, \#Percentage from cases who were married at diagnosis $(n=48)$

Centers for Disease Control and prevention (CDC) expanded the preventive measures to include encouragement of HIV positive cases to disclose their status to their sexual partners. Disclosure may encourage partners to have protected sex and give the HIV negative partner the chance to seek medical care for pre and post exposure prophylaxis.17In Egypt, encouraging married HIV positive cases to disclose to their spouses and discussing the importance of having protected sex is an accepted issue. But regarding singles including men who have sex with men and sex workers, this is not any easy matter as extramarital sexual relations and homosexuality are criminalized and socially unaccepted because of traditions and religious beliefs.18 So, the reported non disclosure of HIV status to sexual partners and having unprotected sex by studied homosexual men and female sex workers can be considered as a major challenge facing HIV/AIDS control measures in Egypt.

Moreover, what was revealed regarding diagnosis of HIV infection among both

The Egyptian Journal of Community Medicine husband and wife at the same time may be attributed to lack of knowledge among those who have high risk behaviors about HIV risk and modes of transmission.

The main limitation of this study is that included people living with HIV were those who regularly attended the HIV treatment center for receiving antiretroviral therapy. So, the obtained results cannot be generalized on those who are living with HIV in Egypt.

\section{Conclusions}

Disclosure of HIV status is a long life process. It is an instrument used by those who are living with HIV to gain needed social and psychological support. Trust on one's response is the main requirement for disclosure. Public health awareness regarding the HIV epidemic, disease nature, modes of transmission and risky behaviors should be integrated in the Egyptian National AIDS program services as well as encouraging HIV screening among those who have high risk behaviors for early detection of cases and application of preventive measures before transmission to their sexual partners.

During counseling, disclosure of HIV status and having protected sex should be discussed with all HIV diagnosed cases irrespective of their marital status.

\section{References}

1. World Health Organization WHO, Eastern Mediterranean Region EMR (2017) . Health topics, AIDS/HIV/STI [-Cited 2017 December 23]. Available from: http://www.emro.who.int/health-topics/aidshivsti/index.html

2. World Health Organization WHO, Eastern Mediterranean Region EMR (2015). Egypt Health Profile:9-10 [Cited 2017 December 23]. Available from: http://applications.emro.who.int/dsaf/EMROP UB_2016_EN_19264.pdf

3. National AIDS Program Egypt (2015). National HIV Program Situation and Gap 
Analysis. [Cited 2017 December 23]. Available from: http://www.unaids.org/sites/default/files/countr y/documents/EGY_narrative_report_2015.pdf 4. Szadkowska DR, Chlabicz S (2008). Who do polish patients inform about their HIV infection?. HIV \& AIDS Review; 7(3): 18-21 5. Shilovskaya MM (2015). Is HIV/AIDS a disability? Stigma and discrimination of people living with HIV and AIDS in the Russian Federation. HIV \& AIDS Review; 14: 9-14

6. El-Zanaty and Associates (2015). Egypt Health Issues Survey 2015. Ministry of Health and Population, Egypt: 51-64.

7. Sowell RL, Phillips KD (2010). Understanding and responding to HIV/AIDS stigma and disclosure: An international challenge for mental health nurses. Issues in Mental Health Nursing; 31(6): 394-402

8. Atuyambe LM, Ssequija E, Ssali S, Tumwine C, Nekesa N, Nannungi A, et al. (2014). HIV/AIDS status disclosure increase support, behavioural change, HIV prevention in the long term: a case for Urban Clinic, Kampala, Ughanda. BMC Health Serv Res; 14: 276

9. Emmanuel W, Edward N, Moses $\mathrm{P}$, William R, Geoffrey O, Monicah B, et al. (2015). Condom use determinants and practices among people living with HIV in Kisii County, Kenya. Open AIDS J ; 9: 104111

10. Kabbash (2015). Assessment of National HIV Prevention response in Egypt

11. El-Sayyed N, Kabbash IA, El-Gueniedy M (2008). Risk behaviours for HIV/AIDS infection among men who have sex with men in Cairo, Egypt. East Mediterr Helath J; 14(4):905-15
12. Kabbash IA, Abdul-Rahman I, Shehata YA (2013). Looking beyond legality: Understanding the context of female sex workers in greater Cairo, Egypt. East Mediterr Helath J; 19(1):24-9

13. Adeoye-Agboola DI, Evans H, Hewson D, Pappas Y (2016). Factors influencing HIV disclosure among people living with HIV/AIDS in Nigeria: a systematic review using narrative synthesis and meta-analysis. Public Health; 136:13-28

14. Linda P (2013). To tell or not to tell: negotiating disclosure for people living with HIV on antiretroviral treatment in a South African setting. SAHARA J; 10(1):17-27

15. Maman S, Van Rooyen H, Groves AK (2014). HIV status disclosure to families for social support in South Africa. AIDS Care; 26(2): 226-232

16. Rapid Response Service (2014). Rapid Response: Disclosure of HIV-Positive Status. Toronto, ON: Ontario HIV Treatment Network: March 2013. Updated November 2014. [Cited 2017 December 23]. Available from:

http://www.ohtn.on.ca/Pages/KnowledgeExchange/Rapid-Responses/Documents/RR662013-Disclosure.pdf

17. Janssen RS, Onorato IM, Valdiserri RO, Durham TM, Nichols WP, Seiler EM, et al. (2003). Advancing HIV prevention: new strategies for a changing epidemic- United States, 2003. MMWR Morb Mortal Wkly Rep 2003; 52: 329-332

18. Kennedy M (2008). HIV: VERDICT on a virus "Public health, Human rights and Criminal law. Victorian AIDS Council Australia: 15 